\title{
Enseñanza de la medicina en Chile colonial durante el siglo XVIII. El catedrático Domingo Nevin y su alumno Pedro Manuel Chaparro
}

\author{
Enrique Laval e Ignacio Duarte
}

\section{Medical education in the Chilean colonial period during 18th century. Professor Domingo Nevin and his disciple Pedro Manuel Chaparro}

This article outlines the beginning of the medical studies at the Universidad de San Felipe de Santiago de Chile on the second half of the $18^{\text {th }}$ century. Dr Domingo Nevin was the first professor of Prima Medicina and Protomedico. Dr. Pedro Manuel Chaparro was the first Chilean student who complete his studies and got his degree at the same university. Both of them had remarkable achievements during the colonial Chilean Medicine.

Key words: University, medicine, smallpox, variolization, vaccine, tuberculosis.

Palabras clave: Universidad, medicina, viruela, variolización, vacuna, tuberculosis.

$\mathrm{E}$ n 1714 el Cabildo de Santiago de Chile inició trámites para solicitar al Rey de España la fundación de una universidad en la capital. Después de reiteraciones y consultas, en 1739 Felipe V firmó el decreto que creaba la Universidad Real de San Felipe de Santiago de Chile ${ }^{1}$. Diecisiete años después, en mayo de 1756 se nombraron los primeros profesores de las siguientes cátedras: Teología, Prima de Leyes, Prima de Cánones, Del Maestro de las Sentencias, Decreto, Instituta, y Lengua. La única cátedra que se creó para los estudios médicos fue la de Prima Medicina, según lo había dispuesto la cédula real ${ }^{2}$.

El objetivo del presente artículo es reseñar la iniciación de los estudios de medicina en el siglo XVIII y los catedráticos que participaron, destacándose la figura del primer profesor y la del primer alumno que cursó todo el plan de estudios en la Universidad de San Felipe.

\section{La cátedra de Prima Medicina y el doctor Domingo Nevin}

Cuando en 1720 el Cabildo de Santiago renovó al Rey la petición para establecer la Universidad, solicitó que se dispusieran dos cátedras de medicina, una de Prima y otra de Método, pero la real cédula de 1739 que erigió la Universidad, sólo aceptó la primera y determinó que su profesor percibiese una renta de 500 pesos anuales ${ }^{3}$.

El único médico que en Chile detentaba el grado de doctor era don Domingo Nevin, por lo cual fue incorporado a la Universidad, como consta en la mención del Libro Primero de Exámenes y Grados:
"En la ciudad de Santiago de Chile, en doce días del mes de abril del año mil setecientos cincuenta y seis, el doctor don Domingo Nevin, que lo es en la Facultad de Medicina, graduado en la Real Universidad de Reims en Francia, se incorporó en esta de San Felipe, y entró en ella por examinador en dicha facultad, por uniforme votación de todos los señores doctores que se juntaron en el claustro, y presente el señor Rector Doctor don Tomás de Azúa Caballero del Orden de Santiago: habiendo

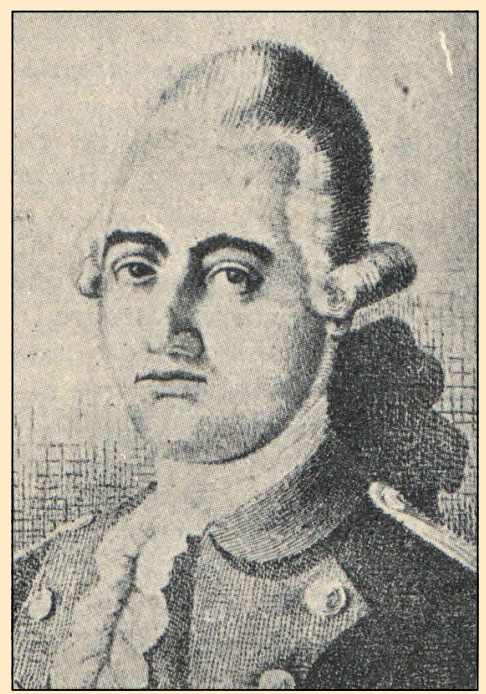

Figura 1. Dr. Domingo Nevin. Fotografía tomada del libro: Laval E M. Historia del Hospital San Juan de Dios de Santiago. Asociación Chilena de Asistencia Social, Santiago 1949, p. 112. Autorizada para publicación en Revista Chilena de Infectología por la familia del fallecido autor.
Pontificia Universidad Católica de Chile.

Facultad de Medicina

Programa de Estudios Médicos

Humanísticos.

Sin conflictos de interés Fuente de financiamiento: Financiado con el presupuesto del programa.

Recibido: 29 de septiembre de 2016

Correspondencia a:

Enrique Laval R.

revinf@sochinf.cl 
precedido la profesión de la Fe y juramento de defender la Purísima Concepción de la Virgen María Nuestra Señora, según está prevenido en las Constituciones, y apadrinándole el R.P. maestro y doctor en Sagrada Teología, fray Juan de Barbosa del Orden de Predicadores: y para que conste, lo pongo en diligencia.- Pedro Luque Moreno, secretario".

Poco más de un mes después de haber así ingresado a la Universidad, se extendía al doctor Nevin su nombramiento de catedrático de Prima de Medicina, que en su texto íntegro a la letra dice:

"En la ciudad de Santiago de Chile, en 19 días del mes de mayo de 1756, el muy ilustre señor don Manuel de Amat y Junient, caballero del Orden de San Juan del consejo de Su Majestad, mariscal de campo de sus Reales Ejércitos, gobernador y capitán general de este reino y presidente de su Real Audiencia, dijo que, atento a hallarse esta Real Universidad de San Felipe en estado de que se nombren los primeros catedráticos que han de leer y enseñar en ella las Facultades respectivas a las $C a ́-$ tedras que la Real benevolencia se dignó asignar, siendo la nominación de las primeras de la regalía: en virtud de las facultades que a Su Señoría competen, nombraba y nombró por Catedrático de Prima de Medicina al doctor don Domingo Nevin, único doctor médico en esta ciudad, por su notoria literatura y demás circunstancias que le hacen digno de ella y que con este nombramiento ocurra al señor Rector de la dicha Real Universidad para tomar la posesión de ella en la forma ordinaria, y se anote todo en los Libros de ella. Y asi lo mandó y firmó Su Señoría.

Don Manuel de Amat. -Por mandato de Su SeñoríaMartín de Martiarena.

De acuerdo con lo que así disponía el presidente Amat, tres meses más tarde, el 5 del inmediato agosto, se establecía lo siguiente:

... "como a las once y media de la mañana, estando en la capilla de esta Real Universidad de San Felipe el señor don Tomás de Azúa, caballero del Orden de Santiago, del Consejo de S.M., Protector fiscal de los indios de este reino y Rector de dicha Real Universidad, y mucha parte del Claustro, congregados a efecto de dar posesión de sus respectivas cátedras a los señores doctores catedráticos nominados por el Superior Gobierno de este reino; hizo exhibición ante dicho señor Rector el doctor don Domingo Nevin, del título de catedrático de Prima Medicina.

Y visto por Su Señoría dicho señor Rector le mandó dar y dio con efecto la posesión de la dicha Cátedra al mencionado doctor don Domingo Nevin, quien la aprehendió en la conformidad que disponen las Constituciones; y a ello fueron testigos el señor doctor don Domingo Martínez de Aldunate, del Consejo de S.M., oidor y alcalde corte de esta Real Audiencia, otros varios señores doctores y los ministros de esta Real Universidad, de que yo, el presente secretario de Cámara e interino de esta Real Universidad, doy fe, como de que lo firmó dicho señor Rector con el doctor catedrático aposesionado.

Don Tomás de Azúa. Doctor don Domingo Nevin. Ante mi. Juan Baptista de Borda, secretario interino ${ }^{3}$.

El doctor Nevin era irlandés, nacido probablemente en el pueblo de Listowel en la parte occidental de la isla. Don José Toribio Medina lo anota como natural de Listun, pueblo de Irlanda, donde debió nacer allá por el año 1722. Se ha supuesto que era francés: quizás su padre fuese francés o de ascendencia francesa, pero su madre era irlandesa, Honoria Mac Hugh. La suposición de que su padre fuera francés se puede haber basado en que Nevin realizó por lo menos sus estudios superiores en la Universidad de Reims, donde obtuvo el título de médico alrededor de 1745 .

Nevin llegó a Chile probablemente en 1753. En marzo de 1754 enfermó gravemente a punto tal que el 19 de ese mes hubo de extender su testamento: debido a su estado dio poder para que testase por él a don Juan Francisco Larraín, a la vez que lo nombraba su heredero universal. En ese documento constan los nombres de sus padres (Daniel y Honoria) y su afirmación de ser católico ${ }^{4}$.

Nevin se recuperó de la dolencia y pudo dedicarse al ejercicio profesional con gran éxito. Es interesante recordar la intervención de Nevin en el juicio por adulterio que hacía años ventilaba don Tomás de Jesús Irigaray, en la Real Audiencia de Chile, quien a temprana edad había constituido su hogar en Santiago, pero no había podido tener hijos. Decidió consultar al bachiller don Pedro Ladrón de Guevara que estaba de paso en la capital. Este había leído y efectuado las pruebas recomendadas por el médico español Luis Lobera de Avila para precisar en tales casos cuál de los cónyuges era estéril. Las aplicó en este caso y determinó que el marido era el causante de que su esposa no pudiera concebir.

Lobera de Avila había publicado en 1551 en Madrid un libro intitulado "Libro del regimiento de la salud y de la esterilidad de los hombres y mujeres y de las enfermedades de los niños y otras cosas utilísimas". En el texto indicaba diversos métodos para diagnosticar la esterilidad conyugal que estuvieron en boga durante más de dos siglos no sólo en los países de habla castellana sino en todos los del viejo continente. Entre estos métodos el bachiller Ladrón de Guevara eligió el que se transcribe: "que orinen ambos, cada uno en una lechuga, y orinen encima: el que primero secare la su lechuga es del que tiene la falta en no engendrar y este experimento es conforme a la razón, porque significa gran calor $y$ abundancia de humores adustos en aquella lechuga que primero se secare".

Al ver marchitarse su lechuga, el marido abandonó definitivamente las esperanzas de dejar descendencia.

Tres años después don Tomás fue presa de angustias cuando supo que su esposa se encontraba embarazada y 
como él no podía ser el progenitor -pues la prueba del bachiller Ladrón de Guevara se consideraba irredargüiblela expulsó del hogar, haciendo caso omiso de sus ruegos y juramentos de no haber faltado a la fidelidad conyugal.

El marido logró sentencia rápida y pudo internar a la esposa adúltera en la Casa de Recogidas, ubicada en lo que es hoy la Plaza Vicuña Mackenna, al pie del cerro Santa Lucía, destinada a recuperar moral y socialmente a las prostitutas.

Más de dos años llevaba encarcelada la señora de Irigaray, deshecha por la humillación y el encierro, cuando llegó el doctor Nevin a Santiago. Parece que el Obispo de la diócesis y los padres de la Compañía de Jesús, cuyo médico era el recién llegado, tenían grandes dudas respecto de la bondad del método aplicado por el bachiller Ladrón de Guevara y aconsejaron a don Tomás de Jesús que expusiera su caso al nuevo físico joven que recién traspasaba la treintena y cuya ciencia era admitida $y$ admirada en la ciudad.

Nevin descartó por ineficaz el valor del método empleado: optó por aconsejar al marido que obtuviese licencia para visitar a su esposa en la Casa de Recogidas y conviviera diariamente con ella algunas horas en su propia celda. Meses más tarde su esposa volvió a quedar embarazada, llegando la paz a la cuitada pareja.

Esta intervención de Nevin fue determinante para difundir su prestigio profesional, al rechazar doctrinas y sistemas absurdos y demostrar conocimientos y visión acordes con el progreso alcanzado por la medicina en los centros europeos.

Respecto a la enseñanza de la medicina, debemos recordar que la Universidad de San Felipe funcionaba en un edificio emplazado donde hoy se encuentra el Teatro Municipal de Santiago y el aula de medicina ubicada en su primer piso, daba a la calle de San Antonio. Dice una relación de la época "que esta aula tenía 11 varas de largo y $6 \frac{1}{2}$ de ancho, entablada, una ventana que daba a la calle, con su reja de fierro"4.

El plan de estudios de medicina comprendía cuatro años lectivos y dos años de práctica en el Hospital San Juan de Dios. La enseñanza teórica se limitaba exclusivamente a la cátedra de Prima de Medicina, es decir, a la lectura de los libros hipocráticos sobre epidemias, pronósticos y aforismos, sin que se tratara antes la anatomía y la fisiología. Nevin tuvo el buen criterio de cumplir con las constituciones universitarias leyendo y comentando a Hipócrates diariamente en las mañanas de 10 a 11:30 h en el aula médica; pero trabajaba cuatro horas todas las tardes con los alumnos en el Hospital de San Juan de Dios, donde procuró dar a conocer la anatomía, los rudimentos de la fisiología, los cuadros patológicos y la enseñanza práctica de la clínica.

El primer alumno de Nevin fue fray Matías Verdugo, que se matriculó el 9 de enero de 1758. Pertenecía a la
Orden de San Juan de Dios. Había estudiado filosofía y teología obteniendo su título de bachiller en arte, y hasta 1761 cursó medicina con Nevin. Luego pasó al convento de su orden en Lima, para proseguir sus estudios médicos en la Universidad Mayor de San Marcos practicando en los hospitales confiados a los hermanos hospitalarios en la capital del Virreinato. Tres años permaneció en Lima; a su regreso se presentó a la Universidad de San Felipe para obtener el título de licenciado y doctor en Medicina, solicitando exención de exámenes por no existir en la Facultad el número de doctores necesario para tomarlos. El claustro accedió a sus peticiones y el 4 de mayo se graduó, sirviéndole de padrino su profesor el doctor Nevin. El hermano Verdugo prestó sus servicios en el Hospital San Juan de Dios. Falleció en septiembre de $1768^{3,5}$.

Al tomar Nevin la posesión de la cátedra el 5 de agosto de 1756 se convirtió en el primer protomédico que hubo en el país, en virtud de la ley que disponía que el profesor de Prima Medicina debía ejercer simultáneamente el protomedicato.

El Protomedicato era un tribunal presidido por el Protomédico. Siendo la más alta autoridad médica, ejercía variadas funciones: tenía jurisdicción privativa y definitiva en todas las causas criminales que se seguían en contra de médicos, cirujanos, sangradores, boticarios y parteras por delitos cometidos en el desempeño de sus oficios; supervigilaba y aplicaba medidas punitivas a quienes ilegalmente practicaban la profesión y estaba facultado para "mirar y catar las tiendas y boticas de boticarios, especieros y demás personas que vendían medicinas, con autorización para quemar en la plaza pública las que se encontrasen falsas, malas, viejas y corrompidas"; dirigía la enseñanza médica y asesoraba a las autoridades superiores en todos los problemas pertinentes a la salud, fijaba los honorarios médicos y poseía la facultad de nombrar tenientes o delegados de protomédico ${ }^{4,6}$.

Nevin usó resueltamente las atribuciones de su cargo: persiguió el charlatanismo y adoptó medidas que llegaron hasta encarcelar a quienes ejercían sin autorización legal y entre ellos a tres religiosos.

En el año 1765 confirmó su calidad al imponer su criterio en el seno de una comisión que estudiaba las medidas para detener el avance de la tuberculosis. En ese año el procurador de la ciudad don Juan José de Santa Cruz se presentó ante la Real Audiencia solicitando se ordenase aplicar medidas que se opusieran a la propagación de esa enfermedad. La Audiencia refirió su estudio a una comisión presidida por el corregidor don Luis Manuel Zañartu e integrada por el doctor Domingo Nevin y los médicos Ignacio de Jesús Zambrano, Eugenio Núñez, Cipriano Mesías y Fray Matías Verdugo. La comisión, a instancia del doctor Nevin, dictaminó que "la enfermedad héctica no es nueva en la ciudad, porque siempre se ha padecido y padecerán mientras no se curaren con 
acierto y a raíz los catarros, pulmonías, puntadas, reumas, empachos arraigados, supresión de evacuaciones críticas de hombres y mujeres y otras semejantes: que no dudan, no obstante de ser tantas las causas de que se origina, que se ha extendido en este vecindario por los vapores y hálitos que salen de la pieza en que está el enfermo, de la cama, ropa y demás cosas que sirven para su curación y uso"".

Después de prestar servicios brillantes al país durante 17 años, Domingo Nevin murió el 6 de julio de 1770 , siendo sepultado en el antiguo Monasterio de Santa Clara. Poseía para su época un gran caudal de conocimientos médicos aquilatado por una práctica de varios años, aunados a su caballerosidad y su carácter recto. Por ello se impuso en el país como el médico más calificado en el ejercicio privado de la profesión, en sus funciones hospitalarias, en la docencia y en afamadas campañas sanitarias ${ }^{4}$.

A la muerte del doctor Nevin la cátedra y, por lo tanto, el protomedicato, pasaron a poder del médico peruano doctor don Ignacio de Jesús Zambrano, médico extraordinariamente sagaz, que en 1773, para curar una grave epidemia de disentería en Concepción, preconizaba el empleo de la cartagena o polvos de ipecacuana.

El tercer y último catedrático y protomédico del siglo XVIII fue José Antonio de los Ríos, quien asumió en 1776 a raíz del fallecimiento de Zambrano ${ }^{3}$. Ríos tuvo importante participación en informes y documentos sobre la profesión médica, epidemias -en particular viruela- y medidas de higiene pública ${ }^{7}$.

\section{La figura del doctor Pedro Manuel Chaparro}

Religioso de la Orden de San Juan de Dios, fray Chaparro inició sus estudios médicos en 1767 bajo la dirección de Nevin, para proseguirlos más tarde con Zambrano. Fue el primer chileno que hizo los estudios completos de medicina en la Universidad de San Felipe, doctorándose allí en julio de 1772. Junto con el doctor José Antonio de los Ríos, fueron las principales figuras de la medicina chilena en el último tercio del siglo XVIII.

En 1765 Chaparro era un juandediano que terminaba su formación teológica y no había comenzado sus estudios médicos. En ese año inició en Santiago las inoculaciones de material de las pústulas variolosas para prevenir la viruela. Este método, llamado variolización, se había empezado a utilizar en 1717 en Europa, contando con los más decididos impugnadores y entre ellos la propia Facultad de Medicina de París. El historiador Carvallo y Goyeneche nos dice que fray Chaparro "comenzó las inoculaciones con tanto acierto que fue el iris que serenó aquella terrible tempestad. Excedieron cinco mil las personas inoculadas y ninguna pereció" 8 .

Veinte años después se inició en el país la inoculación con vacuna antivariólica propiamente tal. El Virrey del Río de la Plata, Marqués de Sobremonte, la había obtenido de los portugueses en Brasil y la remitió extendida entre dos cristales a Lima y Santiago. Fue recibida aquí en el mes de septiembre y aplicada por primera vez por fray Pedro Manuel Chaparro en el pórtico de la catedral de Santiago desde el martes 9 de octubre de 1805. Esto ocurrió antes de la llegada a Chile de Manuel Julián Grajales, miembro de la expedición Balmis enviada por el Rey de España a difundir la vacunación ${ }^{9,10}$.

Al fallecer el profesor Zambrano, fray Chaparro postuló a la cátedra de Prima Medicina, la cual, como se ha mencionado, fue otorgada a José Antonio de los Ríos, en un discutido proceso. No obstante, Chaparro continuó relacionado con la actividad académica en calidad de examinador en la Facultad de Medicina. Además fue catedrático de Filosofía en la Facultad respectiva. Su vocación docente se concretó en la formación práctica de médicos que se formaron bajo su guía en el Hospital San Juan de Dios ${ }^{8}$.

En 1799 el doctor Chaparro fue miembro de una comisión encargada de redactar una propuesta de estatutos (constituciones) propios de la Universidad de San Felipe, puesto que esta se regía por las constituciones de la limeña Universidad de San Marcos. Él fue uno de los tres miembros que firmaron el documento mencionado; pero agregó un programa concebido por él para la carrera de medicina. Este sugería que los estudios debían ampliarse a 5 años. En el primero debía estudiarse la Anatomía mediante la asistencia de los alumnos a disecciones, a las que debían seguir concurriendo en los cursos superiores: para ello solicitaba la habilitación de un anfiteatro anatómico. En el segundo año se debía dedicar a la fisiología o instituciones médicas. En $3^{\circ}$ y $4^{\circ}$ año se enseñaría la patología o historia de las enfermedades del cuerpo humano, y el $5^{\circ}$ año debería dedicarse a la comprensión y exposición de Aforismos de Hipócrates y además Materia Médica, es decir, el conocimiento de los remedios naturales y como se combinan para ser administrados, consultándose los textos de Sydenham y Boerhaave.

Chaparro proponía que los alumnos que aspiraran ser cirujanos seguirían un programa de tres años. En el primero, el curso común de primer año. En el segundo la patología quirúrgica externa: heridas, contusiones, úlceras, dislocaciones, fracturas. En el tercero, operaciones, vendajes y Cirugía Forense ${ }^{11}$.

Se desconoce el destino del trabajo de la comisión redactora de los estatutos: la Universidad de San Felipe no llegó a tener constituciones propias.

Fray Chaparro continuó su infatigable labor hasta que falleció en 1807 después de prolongada enfermedad. Su ejemplo y su obra son testimonio de su saber tan amplio como lo permitían los conocimientos de aquel entonces logrado a través de los más modernos autores médicos y 
de su experiencia clínica y administrativa demostrada en los hospitales de Santiago y Valdivia. Resalta su espíritu de servicio, su audacia y tesón para implantar métodos que aun en España y otros países de Europa no se habían incorporado a la ciencia oficial ${ }^{8}$.

\section{Universidad y Medicina en el siglo XIX}

A raíz del fallecimiento de José Antonio de los Ríos, en 1817 se adjudicó la cátedra de Prima Medicina al único postulante, Eusebio Oliva, chileno, que hizo sus estudios en la misma universidad desde 1782, graduándose de bachiller y doctor en 1793. Oliva tuvo un solo alumno nuevo matriculado en 1817, que no prosiguió sus estudios: esto confirmaba el desinterés por la carrera en Chile en aquella época. En efecto, desde 1758 a 1809 figuraban 33 alumnos matriculados, de los cuales sólo cuatro se habían graduado de doctores y tres de bachilleres en Medicina ${ }^{3}$. Este exiguo número contrasta con los 192 egresados de la Universidad de San Felipe que se doctoraron en Teología o en Leyes ${ }^{12}$.

En 1813 se fundó en Chile el Instituto Nacional destinado a abarcar en un solo establecimiento la enseñanza desde las primeras letras hasta los estudios superiores inclusive.

En 1819 siguiendo instrucciones del Senado que trataba de reponer el Instituto Nacional, abolido durante la Reconquista, cuatro profesores de la Universidad, entre ellos Oliva decidieron seguir como catedráticos en el Instituto; los otros cinco se acogieron a jubilación. En la Universidad se seguía reuniendo el Claustro y eligiéndose rectores, pero reinaba la sensación de que se mantenía una corporación moribunda ${ }^{13}$.

El 10 de agosto de 1833 se inauguró en el Instituto Nacional un curso de ciencias médicas, con un plan de estudios de seis años de duración. En los veinte años previos no había formado ningún médico.

El futuro próximo de la enseñanza médica en Chile fue anticipado por un decreto del Gobierno, fechado el 17 de abril de 1839, que en sus dos primeras cláusulas ordenaba lo siguiente: 1. Queda extinguido desde hoy el establecimiento literario conocido con el nombre de Universidad de San Felipe y 2. Se establece en su lugar una casa de estudios generales que se denominará Universidad de Chile ${ }^{13}$.

Con la promulgación del Decreto que creaba la Universidad de Chile en 1843, la escuela del Instituto quedó incorporada a la Facultad de Medicina de la nueva Universidad, donde los planes de estudio se renovaron periódicamente, y el número de médicos creció en forma acelerada $^{14}$.

\section{Resumen}

Se reseña el comienzo de los estudios médicos en la Universidad de San Felipe, en Santiago de Chile en la segunda mitad del siglo XVIII. El Dr. Domingo Nevin fue el primer catedrático de Prima Medicina y Protomédico. $\mathrm{Su}$ discípulo Dr. Pedro Manuel Chaparro fue el primer alumno chileno que completó sus estudios y se graduó en la misma Universidad. Ambos personajes tuvieron destacada trayectoria en la medicina chilena colonial.

\section{Referencias bibliográficas}

1.- Medina J T. Historia de la Real Universidad de San Felipe de Santiago de Chile. Santiago: Imp. y Lit. Universo; 1928. Tomo I. Capítulo I. La Universidad Real: 1-38.

2.- Medina J T. Historia de la Real Universidad de San Felipe de Santiago de Chile. Santiago: Imp. y Lit. Universo; 1928. Tomo I. Capítulo 3. Don Tomás de Azúa, primer rector: 4556.

3.- Medina J T. Historia de la Real Universidad de San Felipe de Santiago de Chile. Santiago: Imp. y Lit. Universo; 1928. Tomo I. Capítulo 22. La medicina y los médicos: 379-430.

4.- Laval M E. Iniciación de los estudios de Medicina en Chile en el siglo XVIII. Colegio Médico 1953; 5 (2): 34-41.

5.- Medina J T. Diccionario biográfico colonial de Chile. Santiago: Imprenta Elseviriana; 1896: 946.

6.- Laval R E. El protomedicato en el desarrollo de la salubridad en Chile durante la Colonia y la República. Rev Chilena Infectol 2003 (Edición aniversario): 117.

7.- Ferrer P L. Historia general de la medicina en Chile. Talca: Imprenta Talca; 1904. Capítulo 14. Los tres catedráticos de Prima de Medicina de la Real Universidad de San Felipe: 177-86.

8.- Laval M E. Vida y obra de Fray Pedro Manuel Chaparro, médico chileno del siglo XVIII. (Discurso de incorporación a la Academia Chilena de la Historia, leído en junta pública el 16 de mayo de 1957).

9.- Vargas N A, Vial S, Salineros M. Fray Pedro Manuel Chaparro: médico del San Juan de Dios. An Hist Med 2011; 21: 77-82.

10.- Laval R E. Manuel Julián Grajales. Propagador de la vacuna antivariólica en América del Sur. Anatomista y cirujano. Rev Chilena Infectol 2014; 31 (6): 743-5.

11.- El plan de estudios de Medicina del padre Chaparro. n/a. Revista Chilena de Historia y Geografía 1922; 44 (48): 2949.

12.- Cruz-Coke R. Historia de la Medicina Chilena. Santiago de Chile: Editorial Andrés Bello; 1995. Capítulo 29. La educación médica en la Universidad de San Felipe (17561810): 215-23.

13.- Medina J T. Historia de la Real Universidad de San Felipe de Santiago de Chile. Santiago: Imp. y Lit. Universo; 1928. Tomo I. Capítulo 21. La República: 379-430.

14.- Chuaqui B. Breve historia de la medicina. Santiago de Chile: Ediciones Universidad Católica de Chile; Santiago, 2001: 158. 